\title{
Supporting Information \\ Electrooxidation of Alcohols with Electrode-supported Transfer Hydrogenation Catalysts
}

\author{
Megan Buonaiuto, ${ }^{\mathrm{a}}$ Antonio G. De Crisci, ${ }^{\mathrm{a}}$ Thomas F. Jaramillo, ${ }^{\mathrm{b}}$ Robert M. Waymouth*a \\ a Department of Chemistry, Stanford University, Stanford CA 94305 \\ ${ }^{\mathrm{b}}$ Department of Chemical Engineering, Stanford University, Stanford CA 94305
}

Corresponding Author:

Robert M. Waymouth, Tel: (650) 723-4515, Email: waymouth@stanford.edu

Table of Contents

I. General Information $\quad$ S-1
A. Instrumentation
S-1
B. Chemical Transfer Hydrogenation of Acetophenone
S-1
C. Electrochemical Alcohol Oxidation
S-2

II. XPS Detailed Methods

S-3
A. Quantification Parameters
S-3
B. Titanium control XPS
S-4
C. Depth profiling
S-5

III. Chemical Transfer Hydrogenation Controls and Detection

S-6

IV. Additional Electrochemical Experiments and Controls

S-7
A. $\mathrm{Ru}(\mathrm{III} / \mathrm{IV})$ Couple $\mathrm{pH}$ Dependence
S-7
B. NMR Quantification of Acetone
S-8
C. Phosphate CV and Washed Annealed Titanium
S-10
D. Chronoamperometry Quantification
S-11
E. Morphology, Substrate Scope, and Capacitance
S-11

V. References

S-15 
I. General Information. Unless otherwise noted, all chemicals used were purchased from Fluka (99.9+\% trace metal basis), and solutions were prepared using $18.2 \mathrm{M} \Omega$ deionized water from a Millipore system. Pre-annealed titanium foil for the preparation of electrodes was purchased from Alfa Aesar $(0.127 \mathrm{~mm}$, annealed $1100 \mathrm{C} 30$ minutes, $99.99+\%$ trace metals basis) and was used as received. For electrochemical experiments, 2-propanol (Aldrich, Electronic grade $99.999 \%$ trace metals), methanol (Fluka, $>99.9 \%$ ) and ethanol (Fluka, $>99.9 \%$ ) were used to ensure no contamination of detected liquid products.

A. Instrumentation. ${ }^{1} \mathrm{H}$ NMR spectra were recorded on a Varian $600 \mathrm{MHz}$ spectrometer where dimethyl sulfoxide (DMSO) internal standard was used for referencing. All spectra were taken at $20^{\circ} \mathrm{C}$. All chemical shifts are reported in parts per million with multiplicities reported as s (singlet) and d (doublet). Gas chromatography data was obtained on a Shimadzu GC-FID. XPS measurements were acquired at $45^{\circ}$ on a Physical Electronics PHI5000 Versaprobe with $1486 \mathrm{eV}$ Al K radiation. TEM images were taken with an FEI Tecnai G2 F20 X-TWIN Transmission Electron Microscope instrument and SEM images were acquired on an FEI XL30 Sirion SEM.

B. Chemical Transfer Hydrogenation. Chemical $\mathrm{TH}$ using the $\mathrm{Ru}(\mathrm{OH})_{\mathrm{x}} / \mathrm{TiO}_{2}$ nanoparticles, $\mathrm{Ru}(\mathrm{OH})_{\mathrm{x}} / \mathrm{TiO}_{2} / \mathrm{Ti}$ catalyst, and annealed Ti foil control were completed airfree, sealed custom cuvette cells (Starna Cells) assembled in a nitrogen glove box, as depicted below. All solvents and chemicals used were dried, distilled and degassed according to general procedures.

(a)

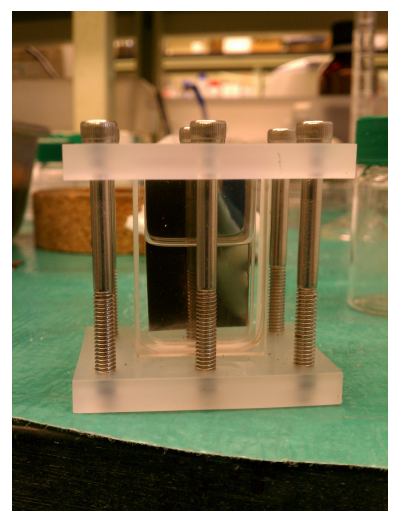

(b)

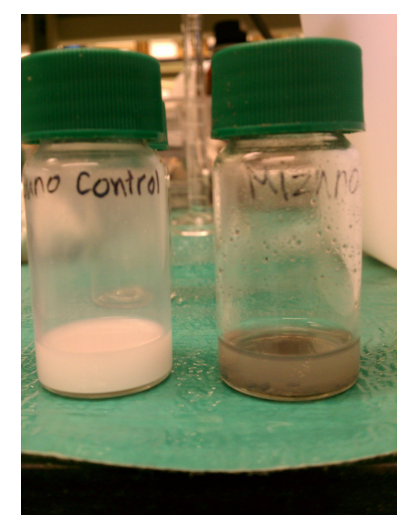

Figure S1. (a) Image of the Starna custom cell used for chemical $\mathrm{TH}$ of $\mathrm{Ru}(\mathrm{OH})_{\mathrm{x}} / \mathrm{TiO}_{2} / \mathrm{Ti}$, Ti electrode, and $\mathrm{Ru}(\mathrm{OH})_{\mathrm{x}} / \mathrm{TiO}_{2}$ nanoparticles for ca $0.001 \mathrm{~mol} \% \mathrm{Ru}$ loading. In order to ensure solvent level was above entire active suface area, electrodes were cut into two, facing the ruthenium deposited sides outwards. (b) Image of $\mathrm{Ru}(\mathrm{OH})_{\mathrm{x}} / \mathrm{TiO}_{2}$ nanoparticle catalyst vials used to independently validate chemical $\mathrm{TH}$ activity for $1 \mathrm{~mol} \% \mathrm{Ru}$ loading. 


\section{Electrochemical Alcohol Oxidation.}

(a)

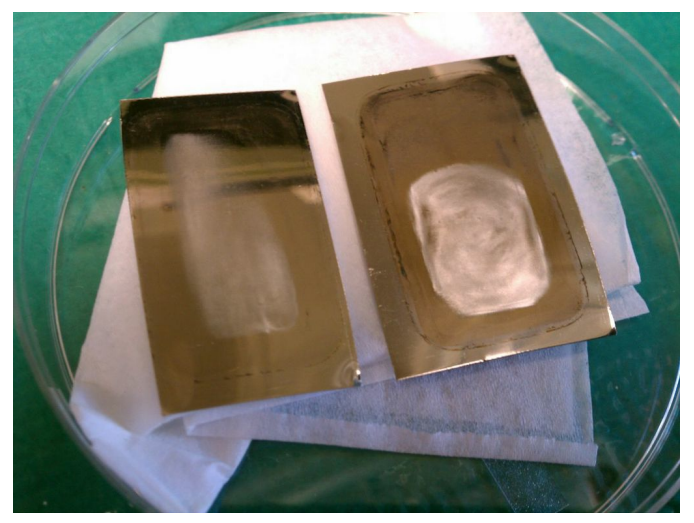

(b)

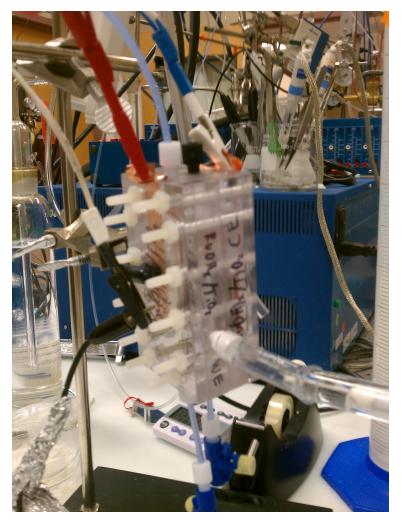

Figure S2. (a) Image of the $\mathrm{Ru}(\mathrm{OH})_{\mathrm{x}} / \mathrm{TiO}_{2} / \mathrm{Ti}$ foil electrocatalyst, showing the brown tint of the deposited area. (b) Image of the constructed custom polycarbonate electrochemical cell. 


\section{XPS Method Details}

A. Quantification Parameters. X-ray photoelectron spectroscopy (XPS) was performed on a PHI 5000 Versaprobe spectrometer with $\mathrm{Al} \mathrm{K} \alpha$ radiation $(1486 \mathrm{eV})$ at 45 -degree angle. Quantification of the foils was carried out using the CasaXPS software package to analyze and model multiple high-resolution scans. Although integration of an isolated peak for elemental quantification was prioritized, the feature overlap required use of model fits for the quantification of $\mathrm{C}$ and Ti. The high-resolution scans were modeled with a Shirley baseline, using the sensitivity factors provided in Table S1 below. In order to ensure accurate quantification, the model was fit with the minimum number of Gaussians across the entire scan width, fixing the peak-to-peak separation, and constraining spin doublets to the degeneracy expected ratio of areas determined $\left(\mathrm{p}_{3 / 2}: \mathrm{p}_{1 / 2}=2: 1, \mathrm{~d}_{5 / 2}: \mathrm{d}_{3 / 2}=3: 2\right)$. After assigning initial binding energy positions, the amplitude and peak position remained the only model parameters unconstrained for optimization. Atomic composition was determined by integration of a single feature for each element, denoted in the table below with an asterisk (*). A consistent integration region was used for each feature, as denoted in the table. A detailed example of a single peak-fitting model is shown below for the $\mathrm{O} 1 \mathrm{~s}$, and the $\mathrm{Ti} 2 \mathrm{p}+\mathrm{Ru} 3 \mathrm{p}$ regions corresponding to the $\mathrm{C} 1 \mathrm{~s}$ region provided in the article.

Table S1. XPS fitting parameters, quantification regions, and experimental peak binding energy use for quantification of $\mathrm{Ru}(\mathrm{OH})_{\mathbf{x}} / \mathrm{TiO}_{2} / \mathrm{Ti}$ electrodes.

\begin{tabular}{|c|c|c|c|}
\hline Feature & $\begin{array}{c}\text { High-Resolution } \\
\text { Integration Region }(\mathrm{eV})^{\text {a }}\end{array}$ & $\begin{array}{l}\text { Sensitivity } \\
\text { Factor }^{b}\end{array}$ & $\begin{array}{c}\text { Binding Energy, eV } \\
\text { (FWHM) }\end{array}$ \\
\hline${ }^{*} \mathrm{O} 1 \mathrm{~s}$ & O 1s, 527-535 & 0.733 & $530.4(2.3)$ \\
\hline${ }^{*} \mathrm{Ru} 3 \mathrm{p}_{1 / 2}$ & Ru $3 p_{1 / 2}, 480.6-493.9$ & 0.74 & $486.0(3.3)$ \\
\hline $\mathrm{Ru} 3 \mathrm{p}_{3 / 2}$ & Ti $2 p+$ Ru 3p, 455-469 & 1.496 & $463.4(1.9)$ \\
\hline Ti $2 \mathrm{p}_{1 / 2}$ & Ti $2 p+$ Ru $3 p, 455-469$ & 0.690 & $464.8(2.1)$ \\
\hline${ }^{*} \mathrm{Ti} 2 \mathrm{p}_{3 / 2}$ & Ti $2 p+R u$ 3p, 455-469 & 1.385 & $458.6(1.3)$ \\
\hline $\mathrm{Ru} 3 \mathrm{~d}_{3 / 2}$ & C 1s+Ru 3d, 279-291 & 1.821 & $286.24(1.9)$ \\
\hline $\mathrm{Ru} 3 \mathrm{~d}_{5 / 2}$ & C 1s+Ru 3d, 279-291 & 2.703 & $282.07(1.9)$ \\
\hline${ }^{*} \mathrm{C} 1 \mathrm{~s} \mathrm{~A}^{\mathrm{c}}$ & C 1s+Ru 3d, 279-291 & 0.314 & $284.6(1.2)$ \\
\hline${ }^{*} \mathrm{C} 1 \mathrm{~s} \mathrm{~B}{ }^{\mathrm{c}}$ & C 1s+Ru 3d, 279-291 & 0.314 & $288.2(2.3)$ \\
\hline
\end{tabular}

\footnotetext{
${ }^{\mathrm{a}}$ The entire region was scanned, modeled and integrated to determine composition

${ }^{\mathrm{b}}$ Relative sensitivity factors used to scale measured peak areas to represent elemental composition

${ }^{\mathrm{c}}$ The width of the carbon feature was fit to the minimum number of curves as the scan resolution hindered determination of the exact number of carbon environments.

* Selected feature for each element integrated to determine atomic composition presented.
} 

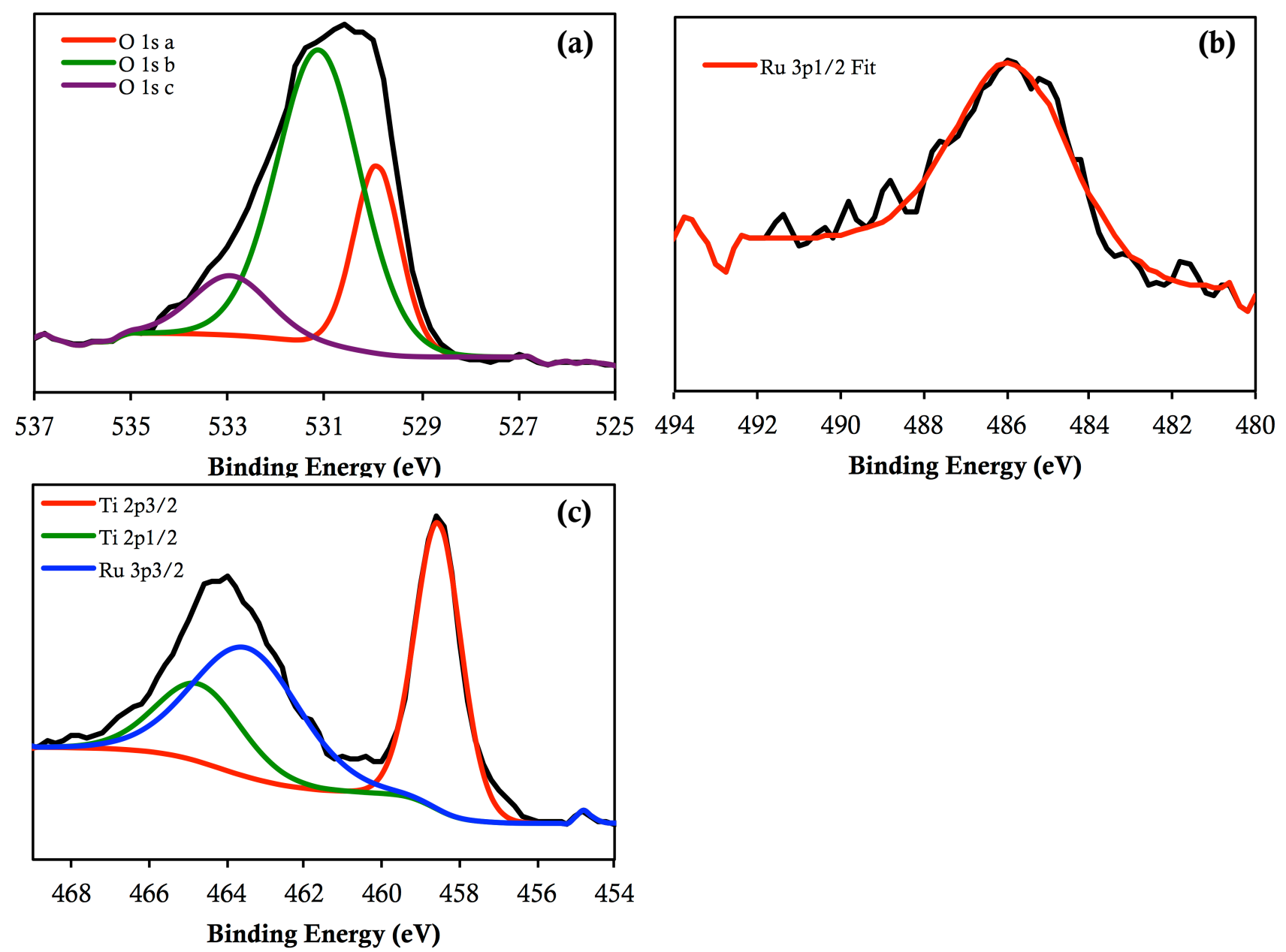

Figure S3. XPS high-resolution scans of $\mathrm{Ru}(\mathrm{OH})_{\mathrm{x}} / \mathrm{TiO}_{2} / \mathrm{Ti}$ catalyst and corresponding model fits to the data (black) (a) $\mathrm{O} 1$ s region (b) $\mathrm{Ru} 3 \mathrm{p}_{1 / 2}$ region (c) combined Ti $2 \mathrm{p}$ and $\mathrm{Ru}$ $3 \mathrm{p}_{3 / 2}$ region.

B. Control Foil. XPS was performed on a standardly degreased annealed titanium foil to further confirm the presence of ruthenium deposition. The annealed foil was sonicated in acetone and 2propanol and soaked on $0.1 \mathrm{M}$ sodium hydroxide for 24 hours to replicate sol gel deposition conditions absent ruthenium chloride trihydrate. The survey scan shows only $\mathrm{Ti}, \mathrm{O}$, as well as $\mathrm{C}$ and $\mathrm{Na}$ contaminants. The Ti $2 \mathrm{p}$ quantification region accurately integrates to the expected 2:1 ratio for Ti $2 p_{3 / 2}: \operatorname{Ti} 2 p_{1 / 2}$. The $\mathrm{C} 1 \mathrm{~s}$ region lacks the features observed for ruthenium. However, it contains multiple carbon environments, consistent with some alcohol and ketone contamination as a result of the degreasing procedure. 

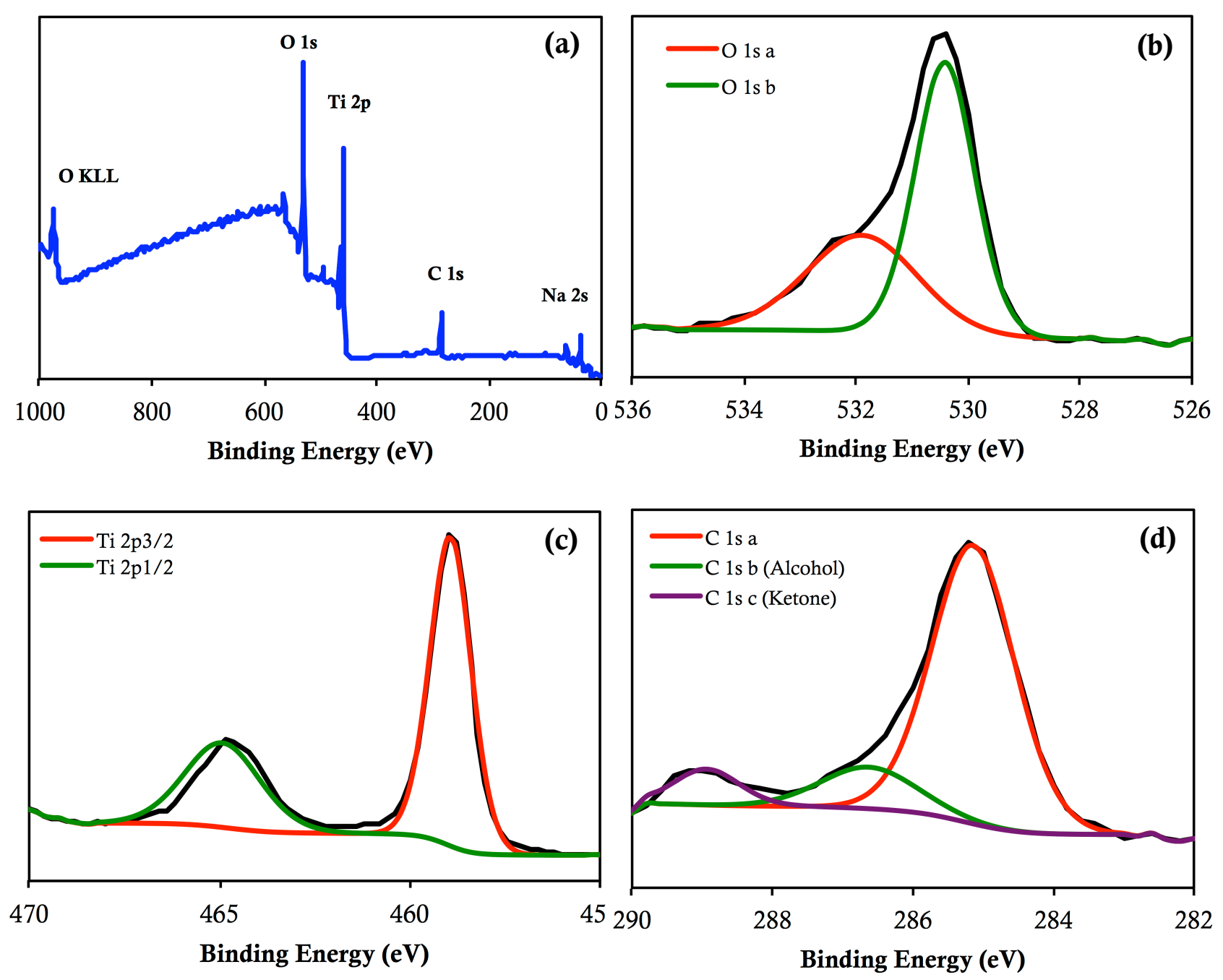

Figure S4. XPS scans of degreased annealed Ti foil and corresponding model fits to the data (black) (a) A survey can display expected $\mathrm{Ti}, \mathrm{O}, \mathrm{C}$ (elemental contaminant), and $\mathrm{Na}$ (base contaminant). (b) $\mathrm{O} 1 \mathrm{~s}$ region (c) $\mathrm{Ti} 2 \mathrm{p}$ region (d) $\mathrm{C}$ 1s region.

C. Depth Profiling. Basic depth profiling of $\mathrm{Ru}(\mathrm{OH})_{\mathrm{x}} / \mathrm{TiO}_{2} / \mathrm{Ti}$ electrode, scanning the $\mathrm{Ti}$ $2 p$ and $\mathrm{Ru} 3 \mathrm{p}$ regions, was carried by sputtering with an argon ion gun at the rate of $1 \mathrm{~nm}$ per minute at 30-second intervals (based on $\mathrm{SiO}_{2}$ expected sputtering rate). Within the $1 \mathrm{~nm}$ of sputtering all surface ruthenium had been removed, as evidenced by a loss of the $\mathrm{Ru} 3 \mathrm{p}$ feature. After $1.5 \mathrm{~nm}$ of sputtering, the Ti $2 \mathrm{p}$ peak had already begun to shift to reduced binding energies exhibiting multiple oxidation states between Ti(IV) and Ti(0). After $3 \mathrm{~nm}$ of sputtering, the Ti $2 \mathrm{p}$ feature had binding energies corresponding to Ti metal. Based upon the estimated escape depth for $\mathrm{RuO}_{2}$ and $\mathrm{TiO}_{2}$, a maximum of $5 \mathrm{~nm}$, we would expect the native $\mathrm{TiO}_{2}$ layer to be between 6 and $8 \mathrm{~nm}$ in width. Previous reports suggest even $2 \mathrm{~nm}$ of $\mathrm{TiO}_{2}$ can contribute to reduce activity due to hole-transport limitations. ${ }^{1}$ 
III. Chemical Transfer Hydrogenation Control and Detection. Multiple independently prepared $\mathrm{Ru}(\mathrm{OH})_{\mathrm{x}} / \mathrm{TiO}_{2}$ nanoparticle catalysts were subjected to the anaerobic catalytic transfer hydrogenation conditions to confirm the activity of report preparation for the conversion of acetophenone to phenylethanol. ${ }^{2,3}$ All nanoparticle catalysts achieved $70 \%$ conversion within 2 hours and reached completion (ca. 95-97\%) within 4 hours, consistent with previous rates. Consistent with previous results, additional minor product peaks were detected $(<5 \%)$ and control $\mathrm{TiO}_{2}$ nanoparticles were found to convert ca. $1 \%$ of the 1phenylethanol to acetophenone in $4 \mathrm{hrs}$.

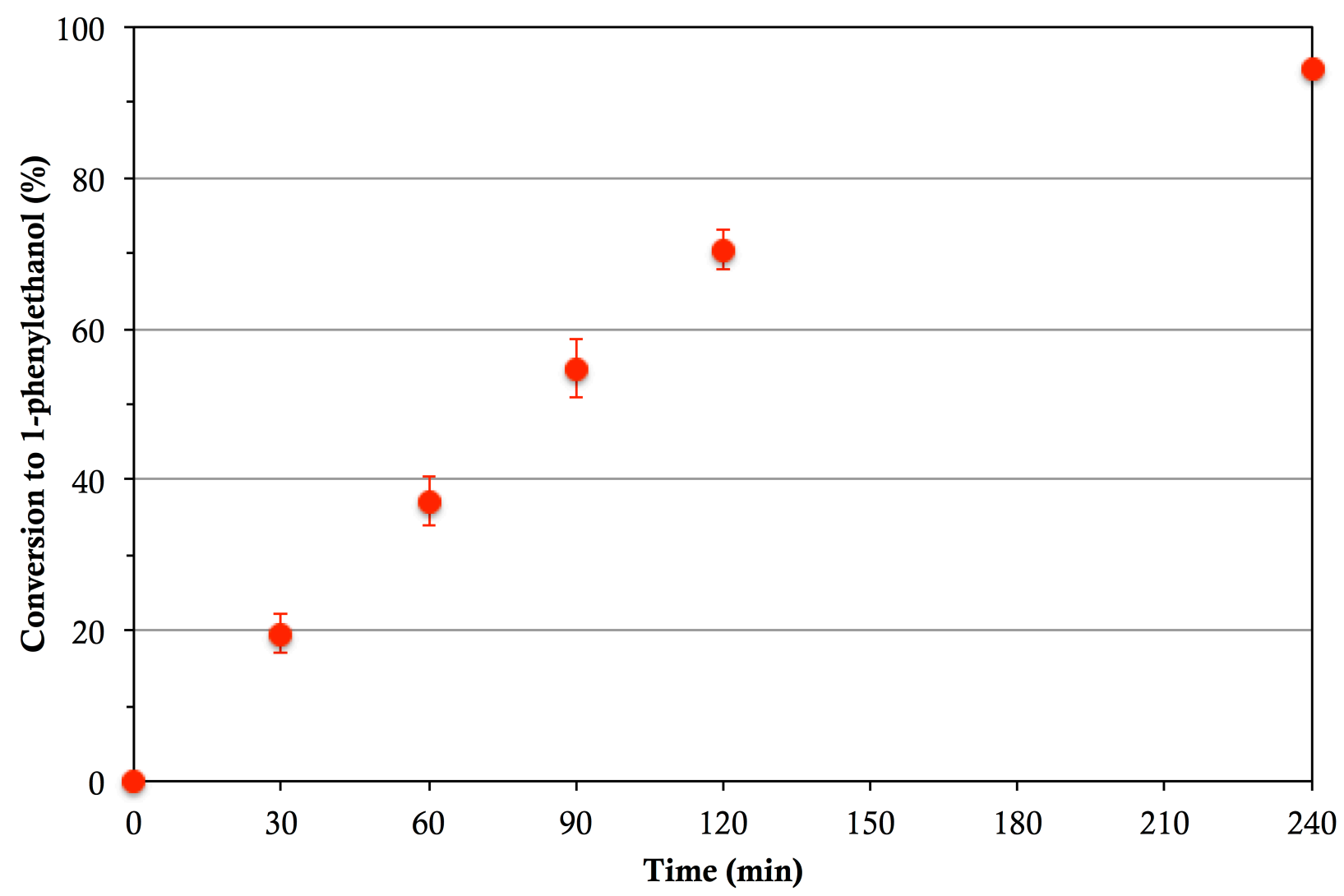

Figure S5. Plotted conversion of acetophenone to 1-phenyethanol by $\mathrm{Ru}(\mathrm{OH})_{\mathrm{x}} /$ Anatase $\mathrm{TiO}_{2}$ nanoparticle catalysts. The reaction was performed under anaerobic conditions, $3 \mathrm{~mL}$ 2-propanol solvent at $81^{\circ} \mathrm{C}$ and a $1 \mathrm{~mol} \%$ ruthenium to acetophenone loading. The $1 \mathrm{~mol} \%$ ruthenium loading was determined based upon the composition previously reported for catalyst preparation ( $2 \% \mathrm{Ru}$ by mass). 


\section{Additional Electrochemical Experiments and Controls.}

\section{A. Ru(III/IV) Couple pH Dependence}

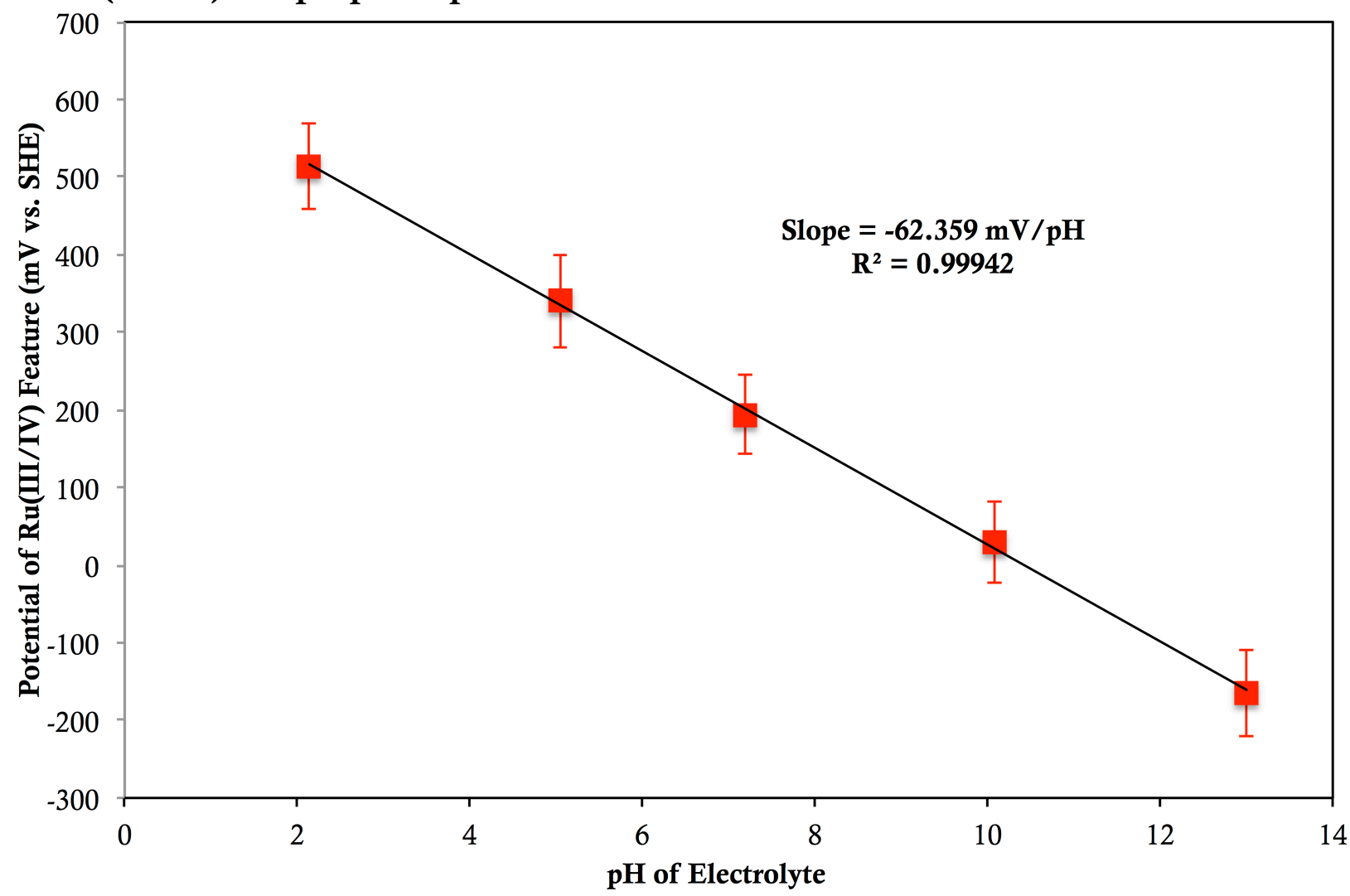

Figure S6. Plot of the $\mathrm{Ru}(\mathrm{III}) /(\mathrm{IV})$ feature potential dependence of the $\mathrm{Ru}(\mathrm{OH})_{\mathrm{x}} / \mathrm{TiO}_{2} / \mathrm{Ti}$ electrode (versus SHE) upon the $\mathrm{pH}$ of the electrolyte solution. The calculated slope is $63 \pm 3 \mathrm{mV} / \mathrm{pH}$ unit, indicating the expected Nernstian response for a proton coupled electron process. The feature position was determined as an average of the peak anodic and cathodic current. Error bars represent the standard deviation across multiple electrode foils.

Conditions: $0.1 \mathrm{M}$ phosphate electrolyte at corresponding $\mathrm{pH}, \mathrm{SCE}$ reference, scan rate of $10 \mathrm{mV} / \mathrm{s}$, degassed. *Due to instability at high and low $\mathrm{pH}$ values, the ruthenium feature for $\mathrm{pH} 2.14$ and 13 was only stable for one scan. 


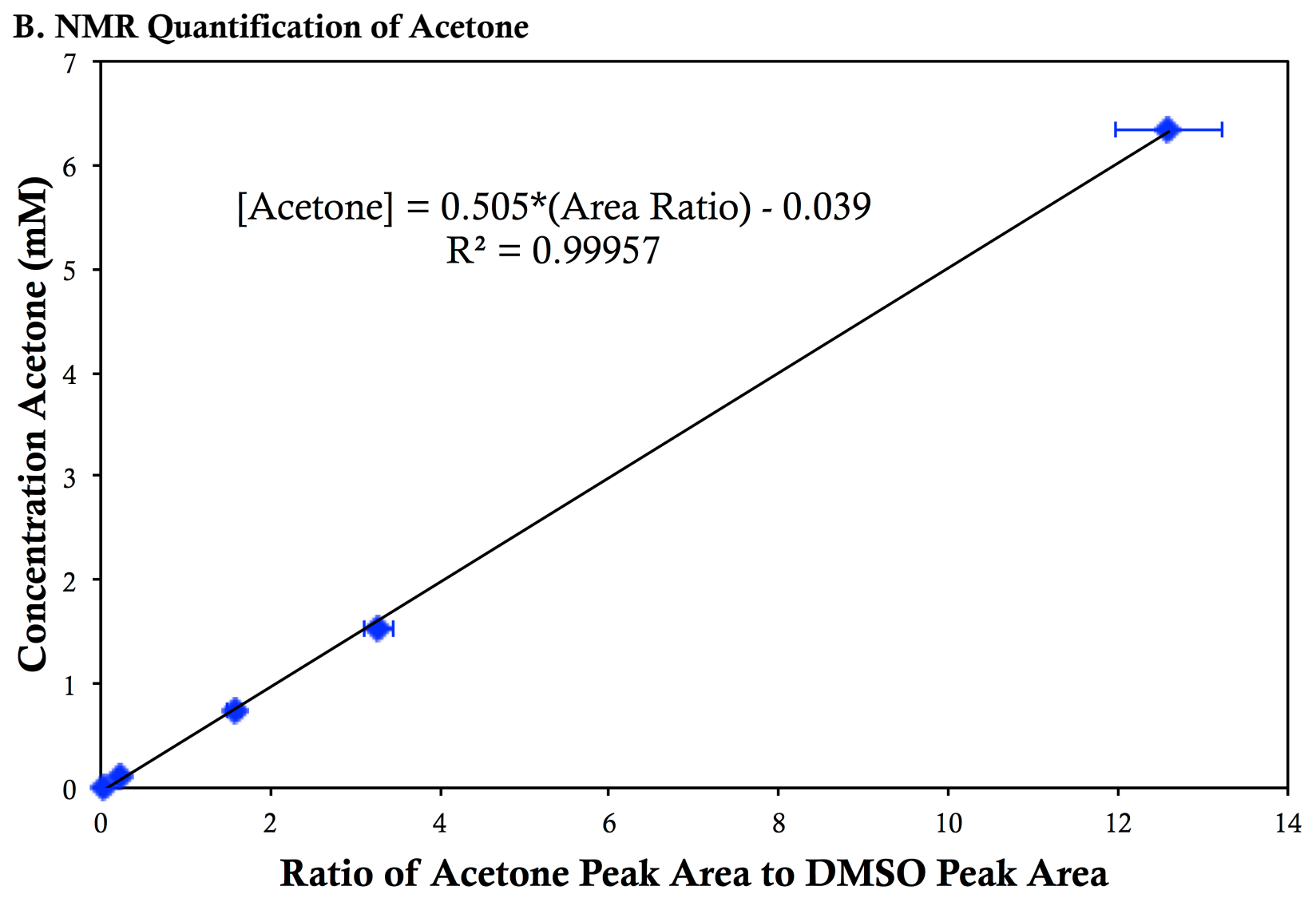

Figure S7. The NMR calibration curve in $\mathrm{D}_{2} \mathrm{O}$ used for quantification of acetone using DMSO as an internal standard. All samples were independently prepared in $0.1 \mathrm{M}$ phosphate buffer. 


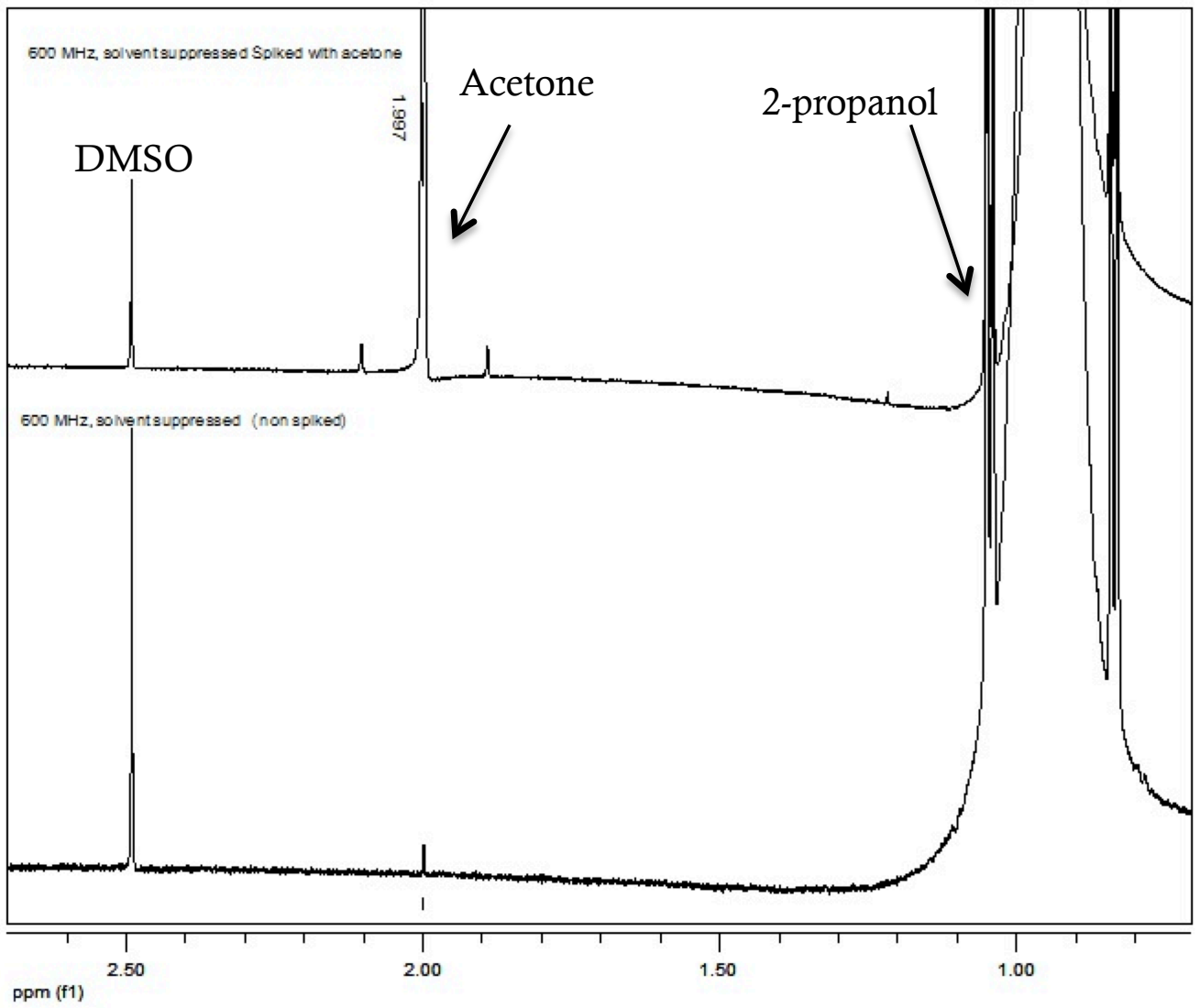

Figure S8. Representative water suppression ${ }^{1} \mathrm{H} \mathrm{NMR}$ in $\mathrm{D}_{2} \mathrm{O}$ spectrum for electrochemical 2-propanol oxidation to acetone by the $\mathrm{Ru}(\mathrm{OH})_{\mathrm{x}} / \mathrm{TiO}_{2} / \mathrm{Ti}$ catalyst. The observed ${ }^{1} \mathrm{H}$ peaks for quantification on the $600 \mathrm{MHz}$ were DMSO (s, $\delta=2.51 \mathrm{ppm})$ and acetone $(\mathrm{s}, \delta=2.01 \mathrm{ppm}$ in $\mathrm{D}_{2} \mathrm{O}$ ), although chemical shifts varied slightly between samples. No additional product peaks were observed between 0 and $12 \mathrm{ppm}$. No acetone contamination was detected for starting 2-propanol. (Below) Electrolyte sample spectrum after 2 hour electrolysis at $0.55 \mathrm{~V}$ vs SCE in pH 7.2 phosphate buffer. (Above) Sample spiked with commercial acetone to confirm product identity. 


\section{Phosphate Cyclic Voltammogram and Washed Annealed Titanium Electrodes}
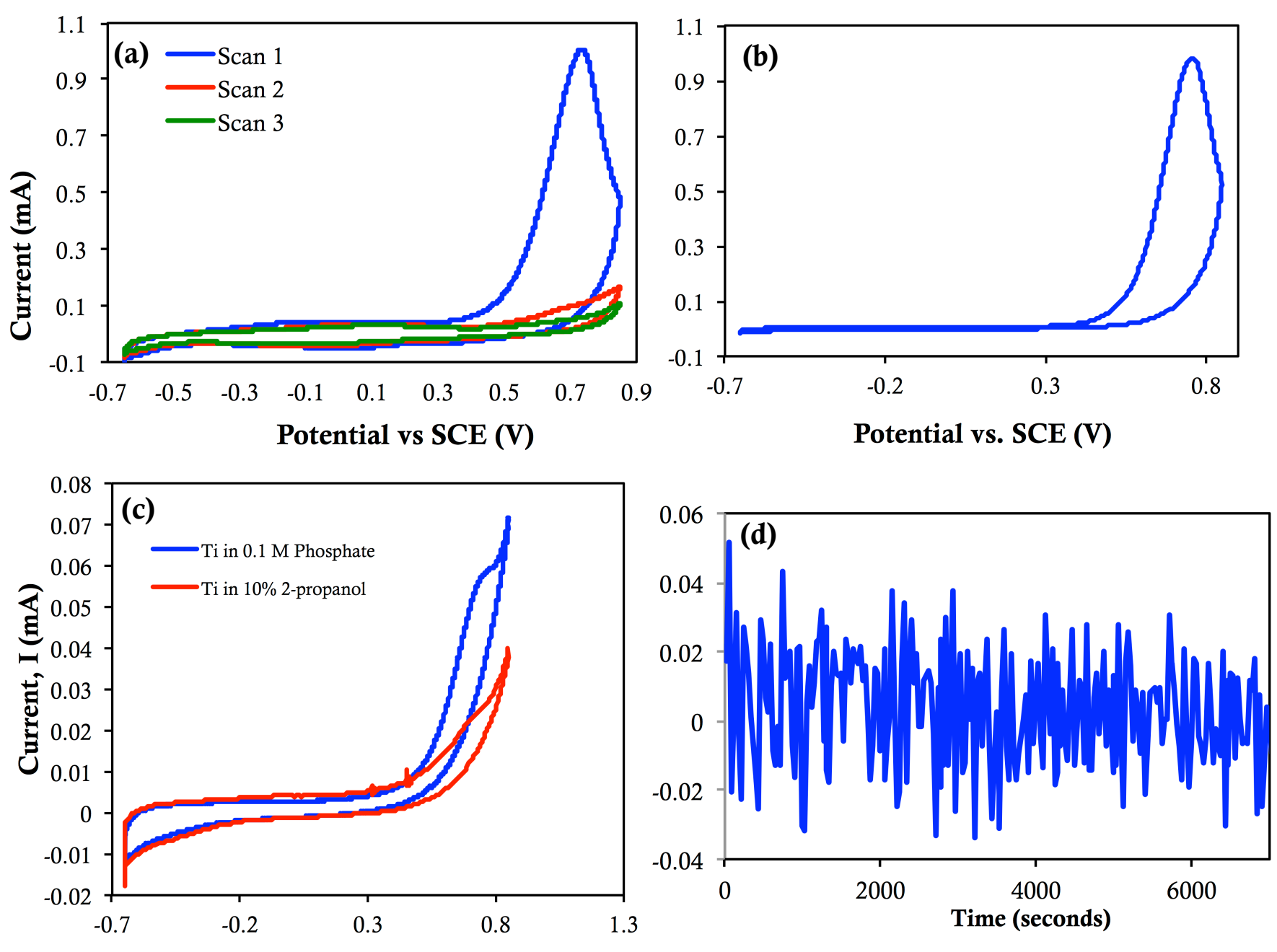

Potential vs. SCE (V)

Figure S9. Cyclic voltammograms

conducted in $0.1 \mathrm{M}$ phosphate buffer ( $\mathrm{pH} 7.2)$ at a scan rate of $10 \mathrm{mV} / \mathrm{s}$. (a) A representative cyclic voltammogram of the $\mathrm{Ru}(\mathrm{OH})_{\mathrm{x}} / \mathrm{TiO}_{2} / \mathrm{Ti}$ electrode over three separate scans, taken in succession without delay. The first scan exhibits a feature at $0.7 \mathrm{~V}$ vs SCE, attributed to the oxidation of $\mathrm{Ti}$ to $\mathrm{TiO}_{2}$. Subsequent scans show a decay in current associated with this feature. (b) A cyclic voltammogram of a washed annealed titanium electrode also exhibits an oxidation feature at $0.7 \mathrm{~V}$, consistent with the oxidation of titanium. (c) Cyclic voltammogram of a washed annealed titanium foil (blue line). Upon addition of 2-propanol (red line), the oxidation feature at $0.7 \mathrm{~V}$ decreases, indicating that isopropanol is not oxidized at these potentials by oxidized Ti foils. (d) Chronoamperometry of a washed annealed titanium foil at $0.85 \mathrm{~V}$ vs SCE in $10 \%$ 2-propanol for 2 hours yielded no observable current for 2-propanol oxidation. ${ }^{1} \mathrm{H}$ NMR analysis of electrolyte solutions after 2, 24, and 72 hours confirmed no acetone was produced. 


\section{Chronoamperometry Quantification}

For a representative 24 hour electrolysis, the total moles of acetone determined by NMR quantification was $9.425 \times 10^{-3} \pm 0.868 \times 10^{-4} \mathrm{mmol}$. The charge required to produce the detected acetone was $1819 \mathrm{mC}$, calculated based on 2 moles electrons required per mole of acetone. The total current integrated during the electrolysis yielded a passed of $2291 \mathrm{mC}$. Thus, if the current due to capacitance charging were ignored, the Faradaic efficiency would be $\mathrm{FE}=1819 \mathrm{mC} / 2291 \mathrm{mC} * 100=79 \%$. As we had observed capacitance charging in the absence of isopropanol, we utilized the following procedure. To account for the capacitance charging the current passed over time for a bulk electrolysis was modeled to the function; $y=A^{*} e^{\left(-k^{*} t\right)}+B^{*} t+C$, with $y$ as current in $m A$, and $t$ as time in second. For the representative example described above, the model parameters were estimated as $\mathrm{A}=0.08689, \mathrm{k}=0.000288, \mathrm{~B}=-2.41 \mathrm{E}-07$, and $\mathrm{C}=0.03356$ which an $\mathrm{R}$-squared value of 0.92534 . Integration of the linear part of the model $\left(B^{*} t+C\right)$ from $t=0$ to $t=86390$ seconds yielded a non-capacitance charge passed of $1999 \pm 11 \mathrm{mC}$. The Faradaic efficiency calculated based upon this model is $91 \%$. As the capacitance charging varied from run-torun (on differently prepared foils), this procedure was performed for 8 independent electrolysis experiments and averaged to yield the reported Faradaic efficiencies reported in Table 1.
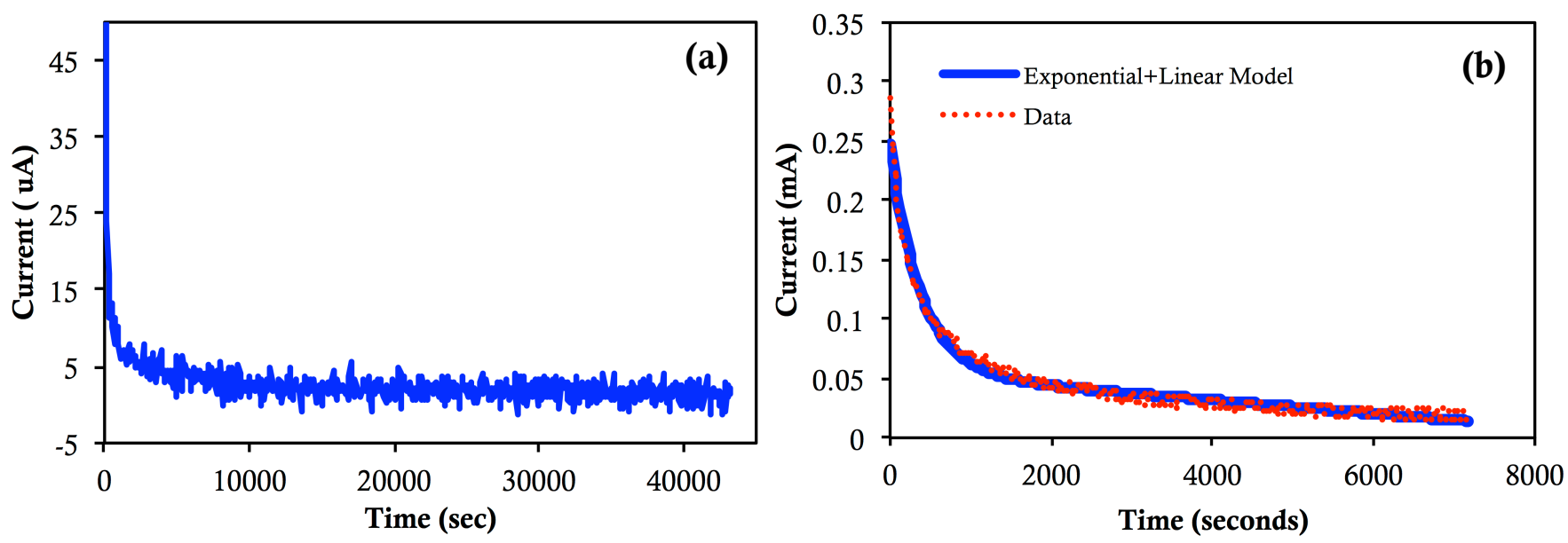

Figure S10. (a) Representative chronoamperometry of a $\mathrm{Ru}(\mathrm{OH})_{\mathrm{x}} / \mathrm{TiO}_{2} / \mathrm{Ti}$ in $0.1 \mathrm{M}$ phosphate buffer at $0.85 \mathrm{~V}$ vs SCE for 12 hours. An exponential capacitance decay and background current of 1-2 $\mu \mathrm{A}$ are observed. (b) A representative graph of the model fit for the chronoamperometry of a $\mathrm{Ru}(\mathrm{OH})_{\times} / \mathrm{TiO}_{2} / \mathrm{Ti}$ electrode at $0.85 \mathrm{~V}$ vs. SCE for 2 hours. Modeling to the function; $\mathrm{y}=\mathrm{A}^{*} \mathrm{e}^{\left(-\mathrm{k}^{*}\right)}+\mathrm{B}^{*} \mathrm{t}+\mathrm{C}$, where the model parameters were solved as $\mathrm{A}=0.19353, \mathrm{k}=0.00265, \mathrm{~B}=-5.66 \mathrm{E}-06$, and $\mathrm{C}=0.05448$ which an $\mathrm{R}$-squared value of 0.97861 . 


\section{E. Morphology, Expanding Substrate Scope, and Capacitance}

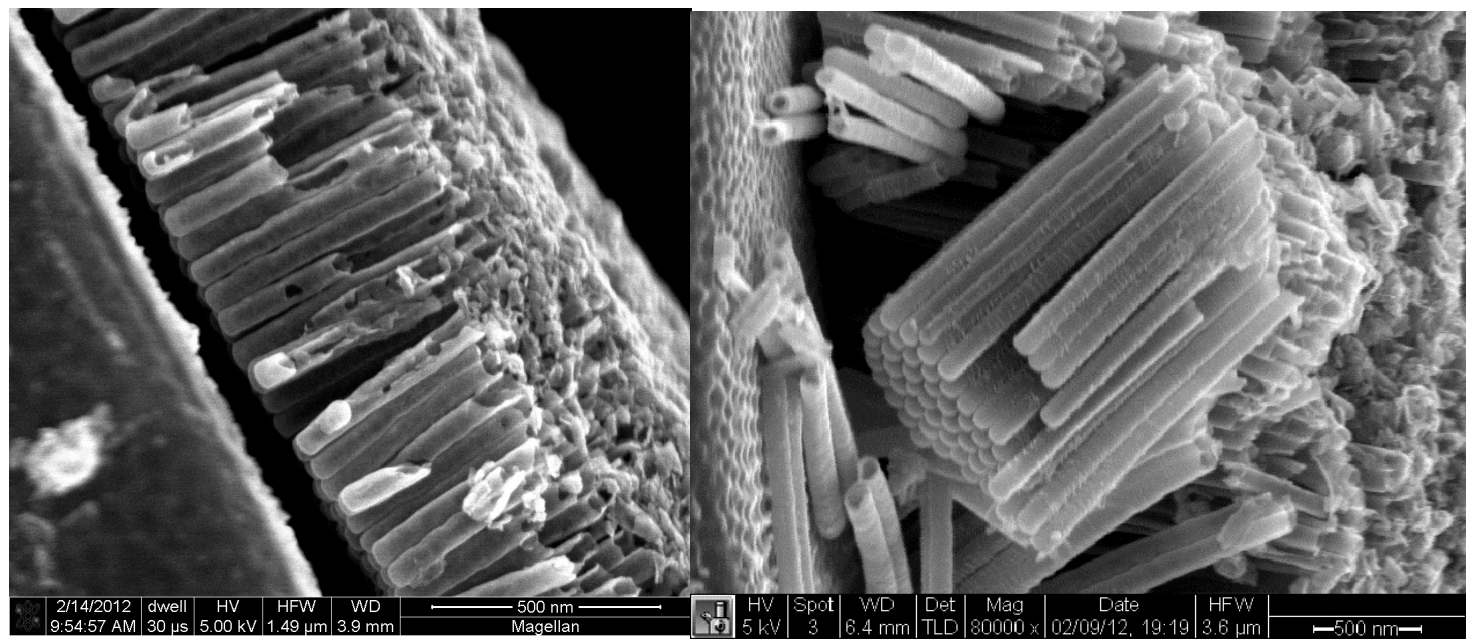

Figure S11. SEM and TEM images of $\mathrm{TiO}_{2}$ nanotubes etched with $\mathrm{HF}$ acid at $120 \mathrm{~V}$ applied potential for 30 minutes. Visible delamination of the nanotubes from the foil contributes to the decreased activity of $\mathrm{Ru}(\mathrm{OH})_{\mathrm{x}}$ deposited on these structures, despite increased surface area of the support.
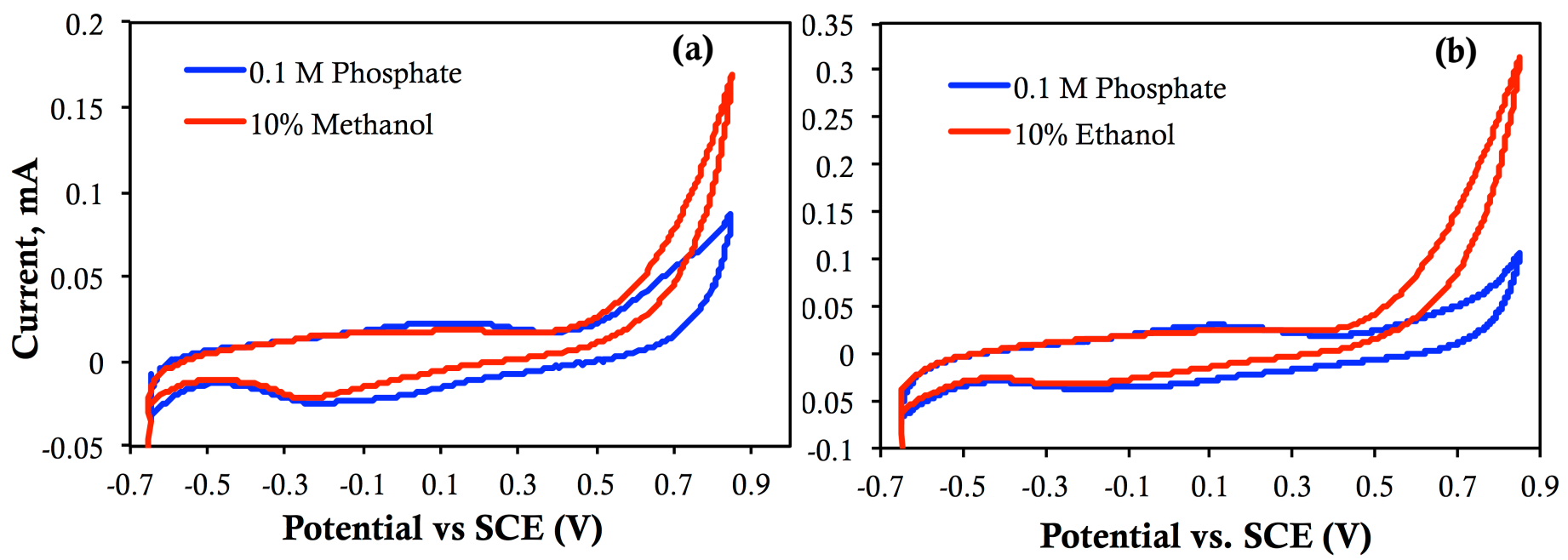

Figure S12. Cyclic voltammograms at scan rate of $10 \mathrm{mV} / \mathrm{s}$ of the $3^{\text {rd }}$ scan in $0.1 \mathrm{M}$ phosphate ( $\mathrm{pH} 7.2$ ) and $1^{\text {st }}$ scan after addition of: (a) $10 \%$ by volume methanol and (b) $10 \%$ by volume ethanol. 


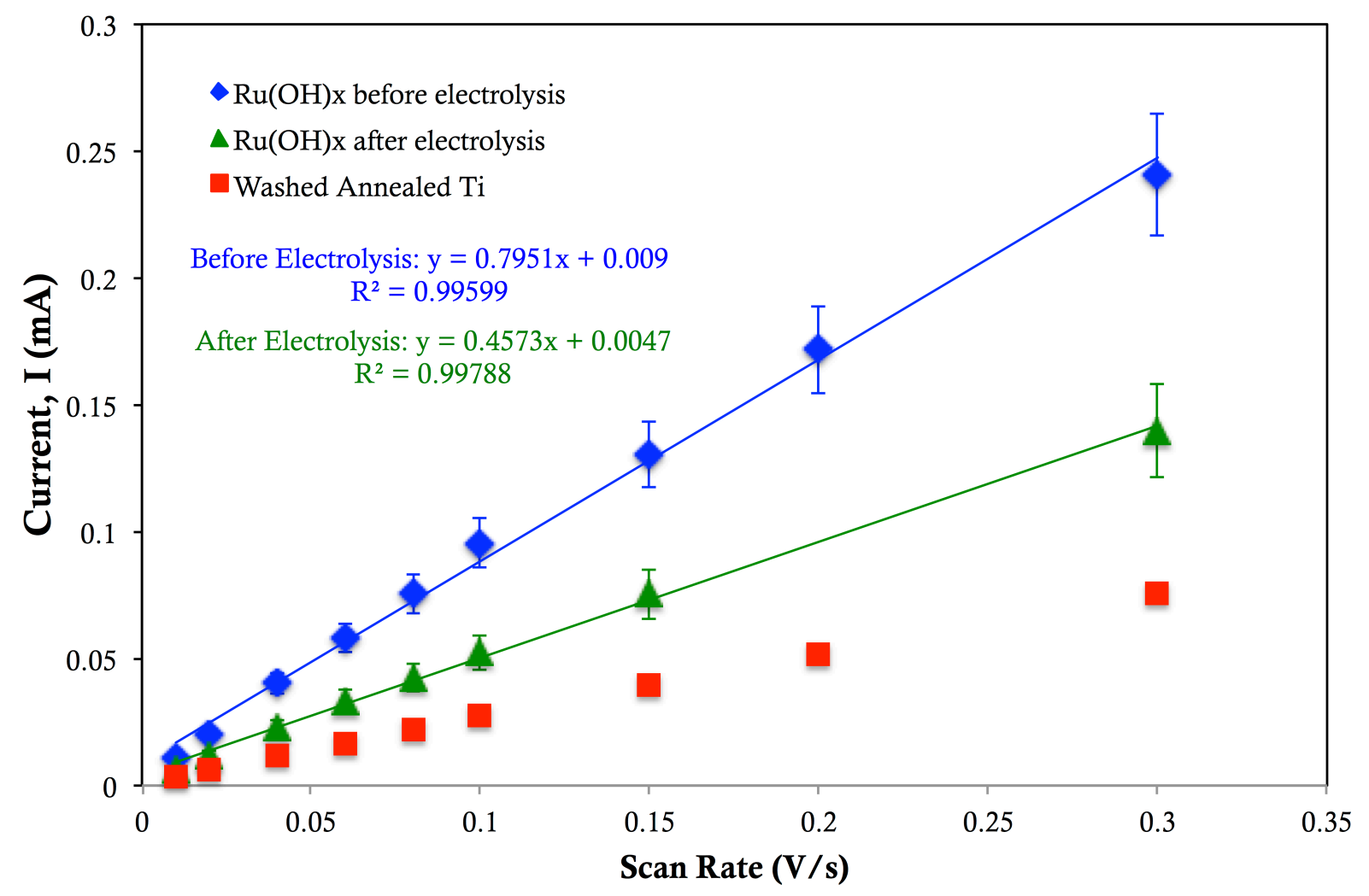

Figure S13. Capacitance curves for the $\mathrm{Ru}(\mathrm{OH})_{\mathrm{x}} / \mathrm{TiO}_{2} / \mathrm{Ti}$ electrode before and after 24 hours electrolysis. For each electrode, the scan rate was varied randomly performing 10 cycles between -600 and $-400 \mathrm{mV}$ vs. SCE at each scan rate. The anodic and cathodic currents at $-540 \mathrm{mV}$ vs SCE were averaged to determine a current for each scan rate. Before electrolysis, the high capacitance (ca. $1000 \mathrm{~F} / \mathrm{g}$ ) is characteristic of an amorphous hydrated ruthenium. The loss in capacitance post-electrolysis (ca. $570 \mathrm{~F} / \mathrm{g}$ ) further confirms loss of active ruthenium and potential loss in electrochemically active surface area as mechanisms of catalyst degradation. 


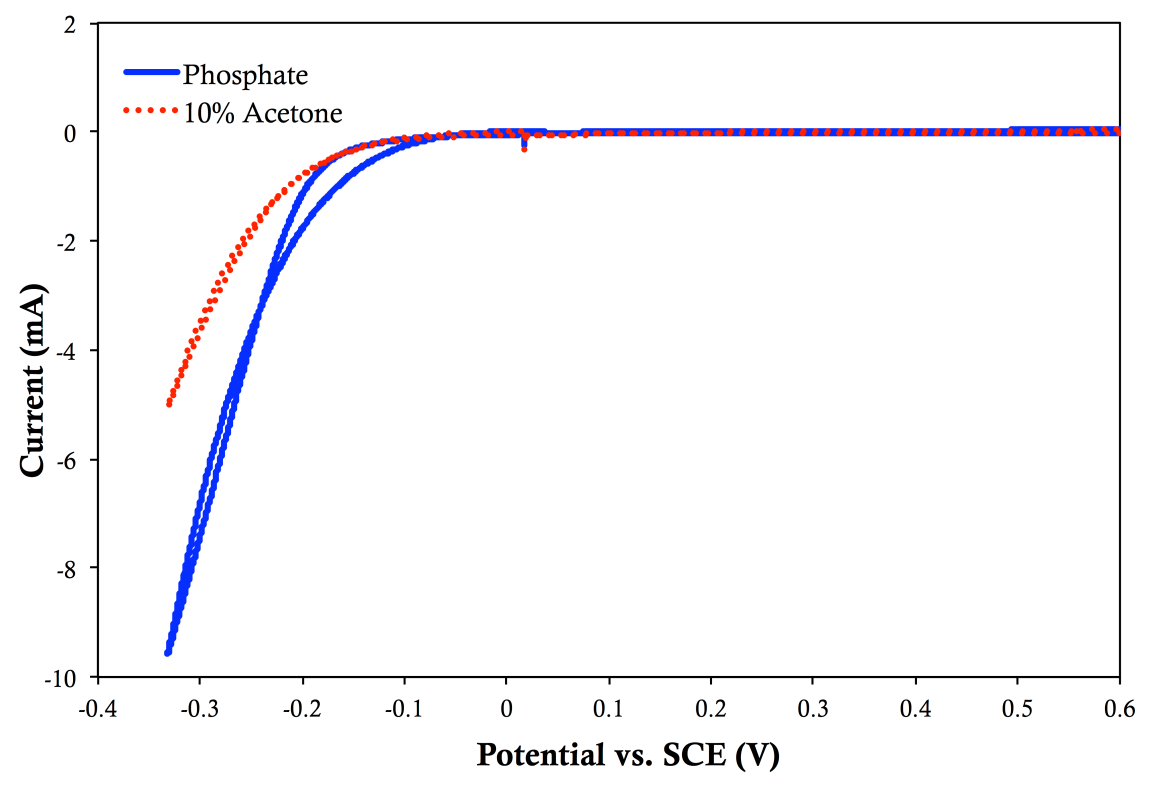

Figure S14. Cyclic voltammogram of a $\mathrm{Ru}(\mathrm{OH})_{\mathrm{x}} / \mathrm{TiO}_{2} / \mathrm{Ti}$ scanned to cathodic potentials in $0.1 \mathrm{M}$ phosphate buffer $(\mathrm{pH} 7.2)$ at the scan rate of $10 \mathrm{mV} / \mathrm{s}$. The blue line denotes the $3^{\text {rd }}$ phosphate scan, and the red dotted line denotes the first scan upon acetone addition. The anodic current observed does not increase upon acetone addition, suggesting the $\mathrm{Ru}(\mathrm{OH})_{\mathrm{x}} / \mathrm{TiO}_{2} / \mathrm{Ti}$ cannot perform the reverse electrochemical reduction, and instead performs hydrogen evolution at modest overpotential $(>400 \mathrm{mV})$. 


\section{References}

(1) Scheuermann, A. G.; Prange, J. D.; Gunji, M.; Chidsey, C. E. D.; McIntyre, P. C. Energy Environ. Sci. 2013, 6, 2487.

(2) Kotani, M.; Koike, T.; Yamaguchi, K.; Mizuno, N. Green Chem. 2006, 8, 735.

(3) Yamaguchi, K.; Koike, T.; Kim, J. W.; Ogasawara, Y.; Mizuno, N. Chem. Eur. J. 2008, 14, 11480. 